14. Симонова Н.И., Соловьева В.В., Саксонов С.В., Митрошенкова А.Е. Редкие мохообразные Самарской области // Известия Самарского научного центра Российской академии наук. 2008. Т. 10, № 5/1. C. 85-94.

15. Саксонов С.В., Сенатор С.А. Редкие и исчезающие виды сосудистых растений, нуждающиеся в охране // Раритеты флоры Волжского бассейна: сб. докл. Тольятти: Кассандра, 2012. С. 210-211.

16. Корчиков Е.С., Макарова Ю.В., Прохорова Н.В., Матвеев Н.М., Плаксина Т.И. Предложения к Красной книге Самарской области // Раритеты флоры
Волжского бассейна: сборник докладов всероссийской научной конференции. Тольятти: Кассандра, 2009. C. 90-96.

17. Ignatov M.S., Afonina O.M., Ignatova E.A. Checklist of mosses of East Europe and North Asia // Arctoa. 2006. T. 15. P. 1-130.

18. Рыковский Г.Ф., Масловский О.М. Флора Беларуси. Мохообразные. Andreaeopsida-Bryopsida. Мн.: Тэхналогія, 2004. Т. 1.437 с.

19. Рыковский Г.Ф., Масловский О.М. Флора Беларуси. Мохообразные. Hepaticopsida-Sphagnopsida. Мн.: Беларуская наука, 2009. Т. 2. 239 с.

\title{
BRYOPHYTES OF THE KRASNOSAMARSKY FOREST
}

\section{(C) 2017}

Bogdanova Yana Andreevna, postgraduate student of Ecology, Botany and Nature Protection Department Samara National Research University (Samara, Russian Federation)

Abstract. 51 species were identified from 2 departments (Marchantiophyta and Bryophyta), 4 classes (Haplomitriopsida, Jungermannopsida, Polytrichopsida, Bryopsida), 11 orders, 28 families and 39 genera during the long-term (from 2010 to 2012 and from 2015 to 2017) studies of bryophytes from the main types of plant communities in the Krasnosamarsky forest (Samara Region). Leading families (Pylaisiaceae, Brachytheciaceae, Amblystegiaceae, Dicranaceae, Orthotrichaceae, Bryaceae, Mniaceae) account for 56,9\% of the total studied bryoflora in the forest. 46 species $(90,2 \%)$ were found in forest communities, 36 species $(70,6 \%)$ in deciduous forests and $25(49 \%)$ - in coniferous (pine and spruce), 9,8\% bryoflora noted at the meadow and steppe sites. 32 species $(62,7 \%)$ of bryophytes grow on the soil, 24 species $(47,1 \%)$ - on the bark of trees, 18 species $(35,3 \%)$ - on decaying wood and 3 species $(5,9 \%)$ - on anthropogenic substrate. Ecomorphic analysis showed that mesophytes $(37,3 \%)$ and mesotrophs $(35,3 \%)$ prevail in the Krasnosamarsky forest. Geographic analysis showed that $41,4 \%$ of bryophytes refer to boreal flora.

Keywords: bryophytes; liverworts; Marchantiophyta; leafy mosses; Bryophyta; Pylaisiaceae; Brachytheciaceae; Amblystegiaceae; Dicranaceae; Orthotrichaceae; Bryaceae; Mniaceae; bryoflora; steppe zone; eco-morphs; geographical element; forest communities; Samara Region; Krasnoarmeysky pinewood; Krasnosamarsky forest.

\section{ВЛИЯНИЕ РЫЖИХ ЛЕСНЫХ МУРАВЬЕВ (НYMЕNOРТЕRА, FORMICIDAE) НА ПРОСТРАНСТВЕННОЕ РАСПРЕДЕЛЕНИЕ МЕЛКИХ МЛЕКОПИТАЮЩИХ В УСЛОВИЯХ НИЖЕГОРОДСКОГО ПРЕДВОЛЖЬЯ}

(C) 2017

Борякова Елена Евгеньевна, кандидат биологических наук, доцент кафедры ботаники и зоологии Мельник Светлана Анатольевна, кандидат биологических наук, доцент кафедры ботаники и зоологии Национальный исследовательский Нижегородский государственный университет им. Н.И. Лобачевского (2. Нижний Новгород, Российская Федераиия)

Аннотация. В данной статье представлены результаты исследования, посвященного изучению хорологического взаимодействия мелких млекопитающих и рыжих лесных муравьев. Цель: изучение влияния муравьев Formica aquilonia Yarr. (Hymenoptera, Formicidae) на пространственное размещение микромаммалий в условиях смешанного леса. Отлов млекопитающих осуществлялся при помощи ловушек Геро, геоботанические описания проведены по стандартной методике, для обработки результатов использован пакет Statistica 6.0. Выявлено, что мышевидные грызуны не избегают муравьиных дорог, несмотря на то, что муравьи - фактор беспокойства. Предположительно это связано с растительностью в непосредственной близости от муравейников и микроклиматом, создаваемым растениями. Полученные результаты по распределению норок микромаммалий в пространстве позволяют говорить о наличии двух групп мелких млекопитающих, характеризующихся различной этологической стратегией: «тяготеющие» - вблизи муравьиных дорог и муравейников, но при оптимальном значении динамической плотности, и «осторожные» - селятся на удалении. «Ядро» группировок составляют, вероятно, особи видов-доминантов: европейской рыжей полевки и малой лесной мыши. Следует отметить, что «тяготение» грызунов к муравейникам нельзя объяснить трофической привлекательностью для них особей Formica aquilonia, поскольку не было получено доказательств использования зверьками муравьев в качестве пищевого ресурса. В заключение делаются выводы о том, что взаимодействие мелких млекопитающих и муравьев в условиях смешанных лесов Нижегородского Предволжья опосредовано, по-видимому, влиянием растительного покрова.

Ключевые слова: норы мелких млекопитающих; растительный покров; расстояние до муравейника; расстояние до муравьиных дорог; гетерогенность пространственной структуры; Нижегородская область; Нижегородское Предволжье; малая лесная мышь; рыжая полевка; пространственная структура сообществ микромаммалий. 
Мелкие млекопитающие, являясь важным звеном естественных экосистем и агроценозов, широко используются в качестве модельных объектов в экологических исследованиях, в том числе и тех, которые затрагивают проблемы антропогенных трансформаций среды. Особое внимание уделяется многочисленной группе мышевидных грызунов. Пространственная структура их популяций обусловлена рядом факторов, в числе которых неоднородность ландшафта и межвидовые взаимодействия. Исследования сосуществования микромаммалий с представителями других видов, сопровождающегося перекрыванием экологических ниш, до настоящего времени являются относительно немногочисленными. Тогда как виды (по крайней мере, «инженерные»), преобразующие собственную среду обитания и существенно воздействующие на хорологическую структуру сообществ, являются в этом плане ключевыми.

Экосистемные «инженеры» модифицируют, поддерживают и создают среду обитания. В то же время многие (возможно, большинство) воздействия ключевых видов включают не только трофические эффекты, но также инженерные [1]. В целом эффект воздействия инженерных видов на разнообразие экосистем является положительным и соответствует $25 \%$-ному увеличению видового богатства. Инженерные эффекты значимее в тропиках, чем на более высоких широтах, в наземных экосистемах «инженеры» проявляли более сильное положительное влияние в засушливых условиях (например, в пустынях). Особенно чувствительно к инженерным воздействиям видовое богатство беспозвоночных [2, с. 867].

Один из основных компонентов большинства наземных экосистем - муравьи. В лесных биоценозах Голарктики самыми значимыми из муравьев являются виды рода Formica. Это объясняется их сравнительно крупными размерами, многочисленностью семей и тем, что многие виды строят хорошо заметные купола из растительных остатков. В лесных сообществах муравьи этого рода играют роль важного фактора, регулирующего, в частности, численность вредителей [3, с. 45].

Взаимодействие двух компонентов биоценоза («териологического» и «мирмекологического») представляет существенный интерес в рамках пространственной экологии и носит, по-видимому, достаточно сложный характер.

Исходя из этого, целью нашей работы являлось изучение влияния муравьев Formica aquilonia Yarr. (Hymenoptera, Formicidae) на пространственное размещение мелких млекопитающих в условиях смешанного леса. Рыжие лесные муравьи выступают в роли потенциального фактора беспокойства для мышевидных грызунов и должны воздействовать на расселение, роющую активность и пространственную структуру популяций последних.

\section{Материалы и методы исследования}

Исследования проводили в летний период 20132014 гг. на территории Пустынского заказника Арзамасского района Нижегородской области. Для оценки взаимодействия мелких млекопитающих с муравьями было заложено 2 участка: контрольный (без муравейников) и учетный, на котором находились модельные муравейники в числе двух, заселенные видом Formica aquilonia (Hymenoptera, Formicidae).
Муравейники выбирали по максимальному числу дорог (численности семьи) и оптимальному состоянию (конический купол, активно развивающиеся гнезда). С муравейников снимались следующие параметры: динамическая плотность (определение осуществляли с помощью рамок в виде проволочных квадратов), высота купола (h, см), общая высота с валом (H, см), диаметр купола (d, cм), диаметр вала $(\mathrm{D}, \mathrm{cm})$. На модельных муравейниках измерялась интенсивность движения на дорогах (количество особей/мин), при этом учитывались особи, идущие в одном направлении в течение 5 мин. через поперечное сечение дороги.

На учетной площадке и контрольном участке проведено геоботаническое описание по стандартной методике с использованием шкалы обилия БраунБланке [4, с. 115]. На учетной площадке заложены 2 стандартные пробные площади $20 \times 20$ м вокруг модельных муравейников. Для детализации геоботанических описаний закладывали серии метровых раункиеровских площадок в пределах каждой пробной площади. Оба участка представлены одной растительной ассоциацией: Tilietum asaroso-lamiosum (Липняк копытнево-яснотковый) и сходны по степени антропогенной нагрузки.

Отлов мелких млекопитающих осуществляли с помощью стандартных давилок конструкции Геро. Отработано 1050 лов./сут., отловлено 162 зверька, относящихся к 3 видам: европейская рыжая полевка Cletrionomys glareolus Scheber., желтогорлая мышь Apodemus flavicollis Melchior., малая лесная мышь Apodemus uralensis L. У отловленных экземпляров снимали стандартные промеры и изымали желудки с последующим анализом их содержимого. Расположение нор микромаммалий относительно муравейников и дорог муравьев проанализировано и закартировано.

Полевые данные переводились в электронную форму с помощью оригинального программного обеспечения EcoDat [5] и подвергались обработке с использованием пакета Statistica 6.0. При сравнении выборок и расчете корреляционной связи использовались непараметрические показатели, что является более корректным для выборок небольшого объема, чем использование параметрических критериев [6, c. 323]. Для выделения сходных групп применялся метод Principal Components Analysis (PCA), являющийся весьма эффективным при обработке экологических данных [7; 8, с. 286].

\section{Результаты и их обсуждение}

Вид Formica aquilonia является хорошо изученным, распространенным в нашей области, и для него характерны большие поселения федеративного типа [9]. Показатели модельных муравейников приведены в табл. 1.

Таблица 1 - Параметры модельных муравейников

\begin{tabular}{|c|c|c|c|c|}
\hline № & $\begin{array}{c}\text { Число } \\
\text { дорог/ } \\
\text { Число } \\
\text { колонн }\end{array}$ & $\begin{array}{c}\text { Численность } \\
\text { колонн (семьи), } \\
\text { тыс. особей }\end{array}$ & D/d, cм & $\begin{array}{c}\mathrm{H} / \mathrm{h}, \\
\mathrm{cm}\end{array}$ \\
\hline M1 & 6 & $162-238(981)$ & $200 / 140$ & $100 / 75$ \\
\hline M2 & 8 & $144-228(1174)$ & $190 / 140$ & $110 / 85$ \\
\hline
\end{tabular}

Примечание. $D$ - диаметр вала, $d$ - диаметр купола, $H$ - высота муравейника, $h$ - высота купола. 
Общая численность в муравейнике М1 составила приблизительно 1 млн. особей, в муравейнике М2 1,2 млн. особей. Муравейники характеризуются наличием в подстилке сухой листвы и еловой хвои, тип гнезда - капсульное с внешним валом и зарастанием вала и купола $(0,1-0,3$, будра и бересклет соответственно).

Анализ характера растительного покрова на учетной площадке выявил наличие факультативных мирмекохоров: пролесника Mercurialis perennis L., медуницы Pulmonaria obscura Dumort. и копытня Asarum europaeum L., что совпадает с данными В.A. Зрянина и Н.А. Новоселовой [10]. Также обнаружены «тяготеющие» к муравейникам крапива двудомная Urtica dioica L. и подмаренник душистый Galium odoratum (L.) Scop., которые находят вблизи муравейников благоприятные условия для произрастания. Кроме того, встречены ландыш Convallaria majalis L., майник двулистный Maianthemum bifolium (L.) F.W. Schmidt, сныть Aegopodium podagraria L. - индифферентные растения по отношению к муравейникам [11].

Население мелких млекопитающих представлено 3 видами: европейская рыжая полевка Cletrionomys glareolus Scheber., желтогорлая мышь Apodemus flavicollis Melchior., малая лесная мышь Apodemus uralensis L. В ходе исследования выявлено, что население микромаммалий на контрольном участке и учетной площадке отличается характером доминирования. На контрольном участке доминирующим является вид Apodemus uralensis, а на учетной площадке - Clethrionomys glareolus. По тесту Краскела-Уоллиса достоверных различий в численности зверьков на контрольном и экспериментальном участках не обнаружено ( $\mathrm{p}>0,05)$.

По данным некоторых авторов, в лабораторных и природных условиях грызуны способны питаться рыжими лесными муравьями [12]. Н.В. Башениной (1977) было высказано предположение о связи между склонностью грызунов к поеданию рыжих лесных муравьев с большим числом (17) микроэлементов в их химическом составе, и особенно с высоким содержанием марганца [13, с. 257]. Результаты лабораторных экспериментов позволяют допустить, что полевые мыши могут эффективно охотиться на рыжих лесных муравьев. Количество убиваемых и тут же съедаемых насекомых и приемы охоты на них дают основания рассматривать муравьев как возможную массовую добычу полевых мышей. Выращенные в лаборатории зверьки проявляли охотничье поведение с первых же встреч с муравьями, демонстрируя полностью все его детали, и эффективно ловили и поедали насекомых. Вероятно, полевые мыши обладают врожденным стереотипом охотничьего поведения по отношению к насекомым, в частности к рыжим лесным муравьям [14].

Нами также было проанализировано содержимое желудков пойманных зверьков на наличие хитиновых остатков насекомых, но результат оказался отрицательным. Это не дает возможности говорить о том, что мелкие млекопитающие используют муравьев как пищевой ресурс.

Для оценки роющей деятельности микромаммалий нами было подсчитано количество нор на контрольном участке и учетной площадке. На учетной площадке обнаружено 25, а на участке без модель- ных муравейников - 42 норы соответственно. Наличие муравейников является решающим фактором для расположения нор мелких млекопитающих, так как контрольный участок по промеренным расстояниям от норок микромаммалий до муравьиных дорог достоверно отличается от учетной площадки $(\mathrm{p}<0,05)$.

В целом расстояние от нор микромаммалий до муравьиных дорог оказывается достоверно меньше, чем до муравейников ( $<0,05$, тест Манна-Уитни) (рис. 1, 2).

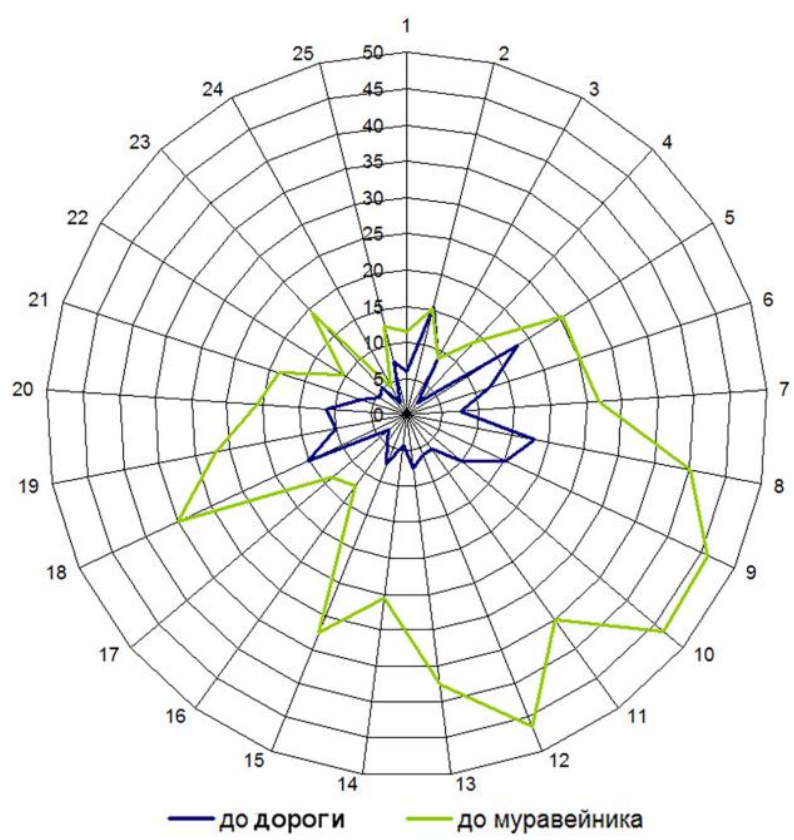

Рисунок 1 - Распределение расстояний от нор до муравьиных дорог и до муравейников (2013 г.)

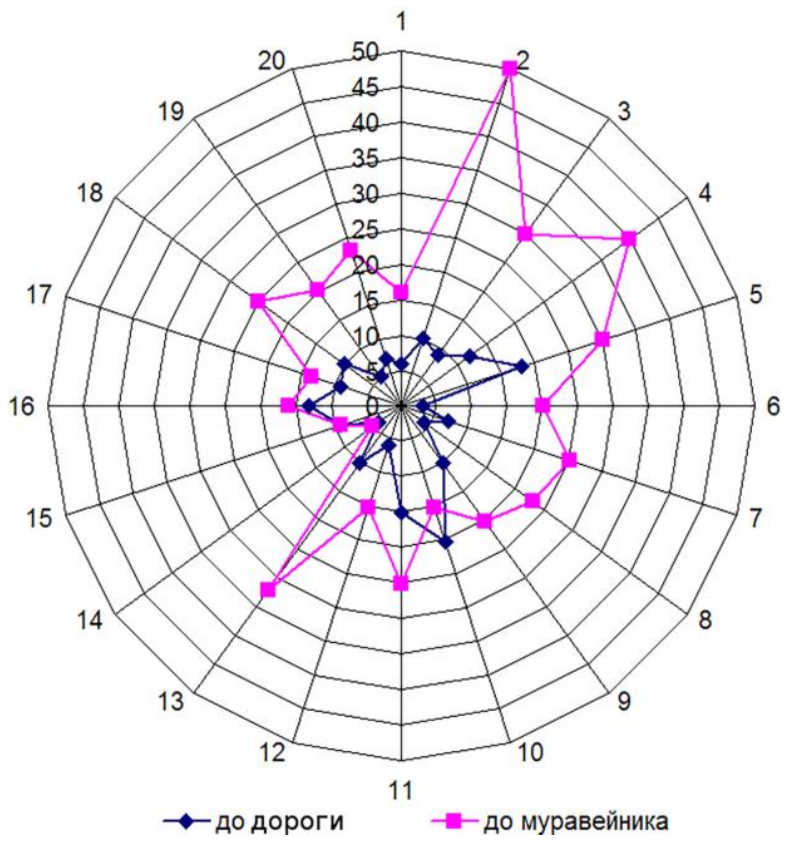

Рисунок 2 - Распределение расстояний от нор до муравьиных дорог и до муравейников (2014 г.)

Распределение следов роющей активности микромаммалий в пространстве носит гетерогенный характер. Мы можем выделить две группы. Часть мелких млекопитающих устраивает норы на достаточно близком расстоянии к фактору беспокойства, не отходя от муравейников далее чем на 20 м и от дорог на 8 м соответственно (условно обозначим их как «бесстрашные», или «тяготеющие»). Возможно, это 
- следствие конкуренции на ограниченных пространствах, когда более молодые животные оттесняются в менее выгодные условия. Еще одна группа «умеренно осторожные», их норы расположены на расстоянии 25-40 м от муравейников и 7-12 м - от дорог.

Существование геторогенной этологической структуры популяций грызунов позволяет избегать полного перекрывания экологических ниш и дает несомненные преимущества. Относительно видового состава выделенных групп мы вправе предположить, что это - виды-доминанты и кодоминанты: рыжая полевка и малая лесная мышь. «Ядро» группировки «тяготеющих», по-видимому, составляют молодые особи, активно расселяющиеся и вытесняемые в более невыгодные условия.

В целом полученные данные свидетельствуют, что грызуны в основном не боятся подходить к муравьиным дорогам и муравейникам, вследствие чего их норы расположены в относительной близости от фактора беспокойства.

Изучение влияния рыжих лесных муравьев на численность и пространственное распределение микромаммалий ведется за рубежом с 1977 г. Браун и Дэвидсон предоставили результаты исследований в пустыне Сонора, предполагающие, что численность как муравьев-жнецов, так и грызунов увеличивалась в ответ на удаление другого таксона. В то же время, явное увеличение числа грызунов после удаления муравьев не было статистически значимым [15, с. 53]. Результаты сходного эксперимента, проведенного в пустыне Чиауа, также не обнаружили значительного эффекта удаления муравьев на популяцию грызунов, в то время как реакция самих муравьев на удаление грызунов была двоякой: вид Pheidole xerophila Wheeler демонстрировал увеличение количества муравьевфуражиров без изменения числа колоний, тогда как у Pogonomyrmex desertorum Wheeler произошло заметное уменьшение числа колоний [16, с. 254].

Подобные рода работы в России были осуществлены в окрестностях г. Новосибирска на участках смешанных рекреационных лесов до появления травостоя. Для учета подбирали участки размером $40 \times 40$ м на территориях рыжих лесных муравьев и контрольные, вне муравьиных поселений, в пределах тех же лесных массивов, сходные по характеру растительности, почвы, освещенности, уровню антропогенной нагрузки и особенностям микрорельефа. Учитывались норы с открытым входом и только обитаемые (остатки пищи, свежий помет, свежие выбросы). Полученные предварительные данные позволили предположить, что роющая активность грызунов, отражающая их относительную численность, на территориях муравьев существенно ниже, чем на контрольных участках [17].

Результаты более поздних исследований в смешанном лесу в окрестностях г. Новосибирска позволили авторам утверждать, что рыжие лесные муравьи и мелкие млекопитающие связаны многоплановыми отношениями, включающими трофические взаимодействия, элементы топической конкуренции и синойкию. Межвидовые взаимодействия этих животных подвержены существенной сезонной трансформации. В периоды своей высокой сезонной активности муравьи, выступая как фактор беспокой- ства, существенно снижают численность и роющую активность мелких млекопитающих на своей территории, а также создают препятствия для их расселения и изменяют показатели подвижности популяций. В периоды сезонного покоя муравьев, которые перемещаются в глубь почвы, муравейники, напротив, привлекают большое количество зверьков: с октября по май до 84\% гнезд муравьев содержат норы мышевидных грызунов и насекомоядных млекопитающих [18].

Муравьи для распознавания присутствия на их территории мелких млекопитающих, возможно, используют обонятельные стимулы. Принято считать, что муравьи не вовлечены в обонятельную коммуникацию. Однако было показано, что Cataglyphis использует запахи для навигации. Например, муравьи распознают пищу или точно определяют неприметный вход в гнездо. В ходе проведенных экспериментов муравьи изучали обонятельные сигналы вдоль своего пути домой и использовали их в отсутствие другой навигационной информации [19, с. 102]. Использование способности различать запахи подтверждает тот факт, что ряд соединений стимулирует антеннальные реакции у муравьев и способен вызвать поведенческие реакции [20, с. 34].

При изучении взаимосвязей компонентов биоценоза необходимо максимально стремиться к приданию исследованию комплексного характера. Связь растительного покрова и сообществ млекопитающих в настоящее время является одним из ключевых моментов пространственной экологии, функционирование зооценоза способствует сохранению структуры фитоценоза. В то же время, зооценоз не существует отдельно, но «вписан» в рамки фитоценоза. Результаты корреляционного анализа по Спирмену подтверждают наличие зависимости между расстояниями от нор мелких млекопитающих до муравейников и до муравьиных дорог с осокой волосистой: 0,52 и 0,41 соответственно $(\mathrm{p}<0,05)$.

Таким образом, для распределения в пространстве нор мелких млекопитающих, и - вероятно - муравьиных дорог и муравейников имеет значение микроклимат, создаваемый под пологом растительного покрова. Мы вправе предположить, что связь между муравьями и мелкими млекопитающими осуществляется на уровне растительного покрова и является опосредованной.

\section{Заключение}

Подводя итог нашего исследования, следует отметить, что микромаммалии не избегают муравьиных дорог и муравейников, несмотря на то, что муравьи - фактор беспокойства. Предположительно это связано с растительностью в непосредственной близости от муравейников, микроклиматом и условиями, которые создаются растениями. Полученные результаты по распределению нор микромаммалий в пространстве позволяют говорить о наличии двух групп мышевидных грызунов, характеризующихся различной этологической стратегией: «тяготеющие, бесстрашные» - вблизи муравейников и дорог, но при оптимальном значении динамической плотности муравьев, и «осторожные» - селятся на удалении от них. «Ядро» группировок составляют, вероятно, молодые особи видов-доминантов, а именно - рыжих полевок и лесных мышей. Существование гетерогенной этологической структуры популяций грызунов позволяет избегать полного перекрывания экологи- 
ческих ниш. «Тяготение» зверьков к муравейникам нельзя объяснить трофической привлекательностью для них особей Formica aquilonia, поскольку нами не было получено никаких доказательств того, что микромаммалии используют муравьев как пищевой ресурс - по крайней мере, рыжая полевка и желтогорлая и лесная мыши.

Авторы искренне благодарят своих коллег В.А. Зрянина и Н.А. Новоселову за помощьь в интерпретачии полученных результатов и критические замечания.

\section{СПИСОК ЛИТЕРАТУРЫ:}

1. Larsen A.L., Homyack J.A., Wigley T.B. et al. Effects of habitat modification on cotton rat population dynamics and rodent community structure // Forest Ecology and Management. 2016. Vol. 376. P. 238-246.

2. Romero G.Q., Gonçalves-Souza T., Vieira C., Koricheva J. Ecosystem engineering effects on species diversity across ecosystems: a meta-analysis // Biological Reviews. 2015. Vol. 90, Iss. 3. P. 877-890.

3. Длусский Г.М. Муравьи рода Формика. М.: Наука, 1967. 236 с.

4. Ellenberg H., Weber H., Düll R., Wirth W., Werner W., Paulißen D. Zeigerwerte von Pflanzen in Mitteleuropa. 2nd ed. Scr. Geobot. 1992. Vol. 18. P. 1-258.

5. Боряков И.В., Воротников В.П., Борякова Е.Е. Использование информационных технологий для организации фитоценариев и обработки геоботанических данных // Бот. Журнал. 2005. Т. 90, № 1. С. 95104.

6. Гланц С. Медико-биологическая статистика. М.: Практика, 1999. 460 с.

7. Борякова Е.Е., Кочетков И.Б. Применение метода главных компонент для анализа зоологических данных // Актуальные вопросы современной науки: сборник научных трудов. Вып. 3. Новосибирск, 2009. C. $10-15$.

8. Трухачева Н.В. Математическая статистика в медико-биологических исследованиях с применением пакета Statistica. М.: ГЭОТАР-Медиа, 2012. 384 с.

9. Коноплева Е.Е. Структура и динамика комплекса муравейников северного лесного муравья Formica aquilonia (Hymenoptera, Formicidae) в разных лесорастительных условиях // Вестник Нижегородского университета им. Н.И. Лобачевского, 2010. № 2 (2). С. 407-412.

10. Зрянин В.А., Новоселова Н.А. Пригнездовые группировки растительности, складывающиеся под влиянием рыжих лесных муравьев (Hymenoptera,
Formicidae) // Біорізноманіття та роль зооценозу в природних і антропогенних екосистемах: матеріали II Міжнародної наукової конференції. Дніпропетровськ: ДНУ, 2003. С. 111-113.

11. Зрянин В.А., Новоселова Н.А., Петрушова Е.С. Анализ растительных группировок вокруг муравейников рыжих лесных муравьев (Hymenoptera, Formicidae) // Поволжский экологический журнал, 2004, № 1. C. 48-51.

12. Panteleeva S., Vygonyailova O., Reznikova Zh. Red wood ants as a perilous temptation for small rodents // 4th Central European Workshop of Myrmecology. Cluj-Napoca, Romania, 2011. P. 61.

13. Башенина Н.B. Пути адаптаций мышевидных грызунов. М.: Наука, 1977. 354 с.

14. Vorobyeva N., Vygonyailova O., Reznikova Zh., Panteleeva S. First count, then hunt: cognitive aspects of ant-hunting in the field striped mouse Apodemus agrarius Pallas. ECBB VI. European Conference on Behavioural Biology. Essen, Germany, 2012. P. 122.

15. Brown J.H., Davidson D.W. Rodent seed-foraging strategies and competition with ants in the Sonoran Desert // U.S. International Biological Program, Desert Biome, Utah State University, Logan, Utah. Final Progress Reports, 1979. Process Studies, RM. P. 52-55.

16. James H.B. Interactions between Rodents and Ants in the Chihuahuan Desert: An Update // The Ecological Society of America. 1994. № 75 (1). P. 252-255.

17. Быкова И.В., Яковлев И.К., Дорошева Е.А., Выгоняйлова О.Б. Предварительные данные о влиянии рыжих лесных муравьев на численность и пространственное распределение мелких грызунов // Муравьи и защита леса: мат-лы XIII всерос. мирмекологического симпозиума. Н. Новгород, 2009. С. 49-51.

18. Пантелеева С.Н., Резникова Ж.И., Выгоняйлова О.Б. Полевые исследования пространственно-этологического взаимодействия мелких млекопитающих с рыжими лесными муравьями // Териофауна России и сопредельных территорий: мат-лы междунар. совещ. Х Съезда Териологического общества при РАН. М.: Товарищество науч. изданий КМК, 2016. С. 316.

19. Buehlmann C., Grahamb P., Hanssona B.S., Knadena M. Desert ants use olfactory scenes for navigation // Animal Behaviour. 2015. Vol. 106. P. 99-105.

20. Vega C. de, Herrera C.M., Dötterl S. Floral volatiles play a key role in specialized ant pollination // Perspectives in Plant Ecology, Evolution and Systematics. 2014. Vol. 16, Iss. 1. P. 32-42.

\section{RED WOOD ANTS (HYMENOPTERA, FORMICIDAE) INFLUENCE ON THE SPATIAL DISTRIBUTION OF SMALL MAMMALS IN THE CONDITIONS OF THE VOLGA UPLAND}

(C) 2017

Boryakova Elena Evgenievna, candidate of biological sciences, associate professor of Botany and Zoology Department

Melnik Svetlana Anatolievna, candidate of biological sciences, associate professor of Botany and Zoology Department

National Research Lobachevsky State University of Nizhny Novgorod (Nizhny Novgorod, Russian Federation)

Abstract. The paper presents the results of research devoted to the study of the spatial interaction of small mammals and red wood ants. The aim of the research was to learn the ants Formica aquilonia Yarr. (Hymenoptera, Formicidae) influence on the spatial structure of Micromammalia populations in the Conifer-Deciduous Forests of the Volga Upland. Trapping of mammals was carried out with traps Gero, geobotanical descriptions were made according to standard methods; the package Statistica 6.0 was used for results processing. It was revealed that mouse-like rodents did not avoid ant-trails despite the fact of the ants disturbance factor. It's presumably due to vegetation in the 
vicinity to anthills, the climate and the conditions created with the plants. The obtained results by the distribution of micromammalia burrows in the space allow us to speak about 2 groups of small mammals with different ecological strategy: «gravitating» which is near the ant-trails and anthills and «careful» which settle over a distance. The group «core» are probably individuals of the dominant species such as bank vole (Cletrionomys glareolus) and pygmy field mouse (Apodemus uralensis). The interaction of small mammals and ants in the mixed forests of the Volga Upland are mediated, apparently, with the influence of vegetation.

Keywords: small mammal's holes; vegetation cover; distance to ant-hills; distance to ant-trails; spatial heterogeneity; Nizhny Novgorod Region; Volga Upland; bank vole; pygmy field mouse; spatial structure of micromammalia communities.

\section{ЭКОЛОГИЧЕСКИЕ ОСОБЕННОСТИ И ВИДОВОЕ РАЗНООБРАЗИЕ ЭПИФИТНЫХ МИКСОМИЦЕТОВ (МУХОМУСЕТЕS) НА СОСНЕ ОБЫКНОВЕННОЙ (PINUS SYLVESTRIS L.) В ЛЕСОСТЕПНОЙ И СТЕПНОЙ ЗОНАХ ЮГО-ВОСТОКА ЗАПАДНОЙ СИБИРИ}

(C) 2017

Власенко Анастасия Владимировна, кандидат биологических наук, научный сотрудник лаборатории низших растений

Власенко Вячеслав Александрович, кандидат биологических наук, старший научный сотрудник лаборатории низших растений

Центральный сибирский ботанический сад СО РАН (2. Новосибирск, Российская Федерация)

Аннотащия. Было изучено видовое разнообразие и таксономическая структура миксомицетов эпифитнокортикуллоидного комплекса в сосновых лесах на сосне обыкновенной. Район исследования расположен в Азиатской части России, на юго-востоке Западно-Сибирской равнины. Видовое разнообразие было выявлено при помощи классического метода «влажных камер», основанного на наличии в жизненном цикле слизевиков покоящихся стадий - микроцист и склероциев, из которых при определенных благоприятных условиях в лаборатории в чашках Петри могут появляться плазмодии, а затем и плодовые тела - спорокарпы. В период с 2008 по 2016 гг. нами в районе исследования было отобрано 720 пакетов для постановки «влажных камер». Постановка опытов с «влажными камерами» была произведена в период с 2008 по 2017 гг. Всего был получен 361 образец миксомицетов. Под образцом подразумевается колония спорокарпов, полученная из одного плазмодия. В результате таксономического анализа на коре сосны выявлено 28 видов миксомицетов, относящихся к 5 порядкам, 7 семействам, 13 родам. Отмечено, что на коре сосны развивается 6 видов миксомицетов, отсутствующих в районе исследования на коре других пород деревьев: Echinostelium fragile, Paradiacheopsis rigida, Physarum auriscalpium, Ph. mutabile, Stemonaria nannengae, Willkommlangea reticulata.

Ключевые слова: миксомицеты; видовое разнообразие; грибообразные протисты; биоразнообразие; слизевики; Азиатская Россия; Западная Сибирь; ленточные боры; лесостепь; степь; Алтайский край; Новосибирская область; таксономическая структура; Pinus sylvestris; субстратные комплексы; субформации; эпифиты.

\section{Введение}

Миксомицеты (Мухотусеtes) - монофилетическая группа свободноживущих плазмодиальных протистов. В жизненном цикле миксомицетов (слизевиков) сочетаются трофическая стадия - многоядерный

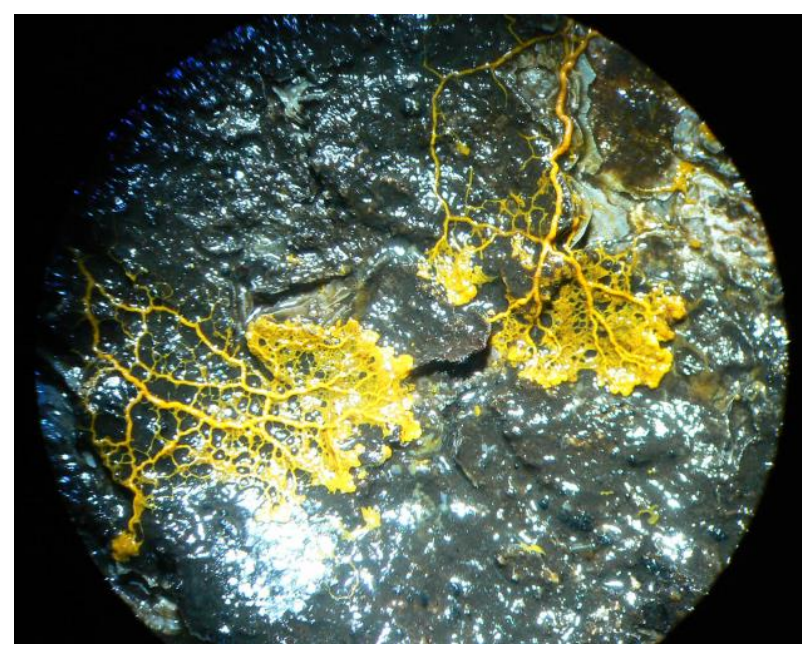

Рисунок 1 - Плазмодий на коре сосны в чашке Петри плазмодий (рис. 1), одноядерные миксамебы, зооспоры и генеративная стадия - спорокарпы (рис. 2).

Доступность подходящих субстратов является одним из важнейших факторов, оказывающих влияние на обилие и распространение слизевиков [1].

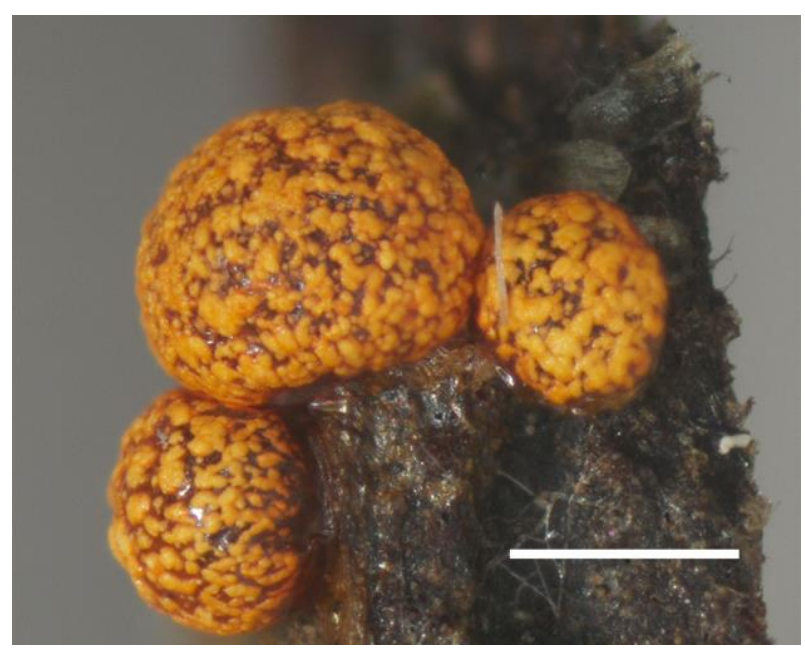

Рисунок 2 - Спорокарпы Physarum auriscalpium в чашке Петри на коре сосны (линейка 500 мкм) 